\title{
General trends in freshwater ecological restoration practice in China over the past two decades: the driving factors and the evaluation of restoration outcome
}

\author{
Juan Wu \\ Tongji University \\ Yanran Dai \\ Institute of Hydrobiology Chinese Academy of Sciences \\ Shuiping Cheng ( $\nabla$ shpcheng@tongji.edu.cb ) \\ Tongji University https://orcid.org/0000-0003-3719-602X
}

Research

Keywords: freshwater ecological restoration, economic growth, restoration outcome evaluation, China

Posted Date: January 3rd, 2020

DOl: https://doi.org/10.21203/rs.2.19860/v1

License: (c) (1) This work is licensed under a Creative Commons Attribution 4.0 International License.

Read Full License

Version of Record: A version of this preprint was published at Environmental Sciences Europe on April 7th, 2020. See the published version at https://doi.org/10.1186/s12302-020-00335-4. 


\section{Abstract}

Background Although freshwater ecological restoration (FER) has undergone an immense development in China either in the number of projects or in the spatial scale of implementations, a dearth of clear and comprehensive trends in this field is still a particular concern. We conducted a literature survey through searching the database of Web of Science between 1998-2017.

Results A total of 2047 publications were hit and 198 of them were finally retained after manual screening. The number of studies in this field has been steadily increasing in recent years and their provincial distribution is positively correlated with GDP growth and the investment to pollution control and protection, suggesting that economic development is a key driving factor of FER practice. Among the remained articles, nearly half (46.5\%) focus on lake ecosystems, and $34.8 \%$ and $32.8 \%$ of the studies believe that land reclamation and eutrophication are the top two causes of freshwater ecosystem degradation. The overarching target of the restoration is biodiversity increase (31.4\%), followed by water quality improvement $(24.7 \%$ ) and ecosystem services (23.9\%). Revegetation is the dominant restoration approach (40.9\%). Reference sites for assessment of restoration projects are normally control areas or locations without intervention (60\%), or the status of the targeted sites before the interventions. For the restoration outcome evaluation, $86 \%$ of the studies present positive outcomes in terms of water quality improvement, and $79 \%$ have improvement in biological features. The most frequently monitored organisms are macrophytes (31\%), then followed by benthos as indicators of ecological condition.

Conclusions The literature research indicated that economic growth, water pollution and investment into environmental protection are the main driving factors of FER practice in China. Additionally, the effort of restoration and evaluation over the past two decades has not been limited to improving hydrological function and water quality, but also pay increasingly more attention to biological processes and ecological integrity, and further the ecosystem services in recent years. However, the lack of long-term monitoring and socioeconomic attributes considered in restoration success assessments are still particular issues needed to be addressed in the future FER researches and projects.

\section{Background}

As a young applied science, ecological restoration has undergone considerably rapid growth over the past decades around the globe. Due to the wide dependence of human activities on freshwater, the freshwater ecological restoration (FER) have become a more highlighted topic compared to terrestrial ecosystem restoration. The issues of water resource shortage and water pollution, inevitably with more severity in developing regions, make FER increasingly urgent and vital. Over the past decade, a large number of FER related research have been published in a broad range of scientific journals, in which theoretical development, modulation of ecological structure and function, restoration or mitigation approaches, and evaluation of restoration outcomes are the major research objectives. However, it seems that the focus of restoration has been shifting from achieving a previous or least-disturbed ecological state to a more utilitarian purpose: ecosystem services $[12,24]$. The shift of restoration goal has been reflected in the 
studies and findings over the past decades, with a focus on the roles of particular species in supporting the ecosystem processes or products useful to humans [20].

In the unprecedented wave of economic development and urbanization, China has been undergoing a tremendous freshwater crisis. Water quality of the largest rivers, lakes and reservoirs dramatically declined in the 1990s and 2000s. Environmental communiqués issued by the Ministry of Environmental Protection indicate that the seven major river systems had the worst water qualities during 2001-2004, with over $26 \%$ of monitored river sections having water qualities worse than Grade $V$ under the Environmental Quality Standards for Surface Water of China, while back to 1991, such water quality level had not been observed. The deterioration of lakes and reservoirs is even severer than the rivers, $48 \%$ of monitored water area reached the water qualities worse than Grade V in 2006. In addition, the structure and function of freshwater ecosystems have been sharply degraded, mainly due to land reclamation, water shortage, water pollution and climate change $[3,32,34]$. Despite the abundant total water resource, the annual per capita renewable freshwater availability is $2007 \mathrm{~m}^{3}$ in 2018 , only accounting for $25 \%$ of the world's average [21]. The water scarcity, aggravated by pollution, leads to the difficulties to meet the basic environmental and ecological demands for water in many freshwater ecosystems [15]. Moreover, the freshwater wetland area has shrunk by $8.82 \%$ from 52.43 million hectare in 2003 to 47.81 million hectare in 2013 [31]. The habitat losses was resulted from the highly intensified land reclamation and climate change [34].

The degradation of ecological processes and ecosystem services have raised increasingly more awareness of scientists, the public and governments in China, thus promoting an accelerated growth of FER research and projects during the past 20 years. Since the beginning of 21th century, the Chinese central government has launched a number of national water pollution control projects, aiming to substantially constrain the water pollution and ecological degradation of important watersheds, including the most polluted "three rivers" and "three lakes". The investment into water pollution control increased from 493.7 billion CNY (ca. US\$ 71.7 billion) in 2008 to 953.9 billion CNY (ca. US\$ 138.4 billion) in 2017 [19]. Given the specific government structure and institutional characteristics of China, the FER projects, particularly large-scale ones, are mostly policy driven and invested by different levels of government. In addition, the dependence on political and economic progress in the evaluation and promotion of governmental officials determines that the implementation and outcome evaluation of restoration projects typically focus on short-term political and economic benefits rather than long-term environmental and ecological effects $[1,6,17]$.

A focus on design and engineering approaches to recover the hydrological or geomorphological characteristics of the targeted ecosystem is shared by a large proportion of the research and projects $[4,10,40,41]$. Stabilizing the bank line, altering the slope and hydrology, manipulating the flow regime and dredging the sediment are usually employed in the implementations of these projects $[14,18,43]$. More recently, a focus on water quality improvement have driven many FER implementations, in which an array of in-situ physicochemical and biological techniques has been developed and applied with an attempt to remove or stabilize pollutants and nutrients in water column or sediment $[8,25,35]$. Among these 
techniques, revegetation has gained considerable attention. Aquatic macrophyte populations were usually rebuilt as an approach to absorb the nutrients and maintain the clear water, rather than as a critical structural feature of ecosystem or as a goal of the restoration $[2,5,33,38,42]$.

There are some published studies reviewing on the theoretical and practical progresses of FER in China $[29,35,39]$, most of which merely focus on summarizing policy changes, or providing general descriptions of developing trend, but lacks a quantitative assessment on this topic. Our goal is to comprehensively comb the developing processes of FER practice over the past two decades and to identify the current status of FER efforts in China, hoping it could offer a reliable guidance for the field in the future.

\section{Methods}

Literature search

A literature search was conducted in January 2018 using the ISI Web of Knowledge database (http://apps.webofknowledge.com) to obtain the publications from 1997-2017 with the methods outlined by Kollmann et al.[13]. The database includes the Web of Science core collection, Chinese Science and Citation Database (CSCD), Derwent Innovations Index, KCI-Korean Journal Database, MEDLINE, Russian Science Citation Index and SciELO Citation Index. Aside from international journals, due to inclusion of CSCD in the database, most of predominant Chinese journals published in China were also the targets of the search. We used the following querying string to conduct the search:

TITLE $=$ (restor* OR recover* OR conserv* OR reestab* OR revegeta*OR reintro* OR rehabil* OR rewet*OR repair*) AND TOPIC $=($ freshwater OR stream OR waterway OR channel OR river OR lake OR estuary OR pond OR marsh OR swamp OR wetland OR watershed OR basin) AND Research Area= (biological sciences OR environmental sciences ecology) AND Country= (China OR PRC OR People's Republic of China $)$

The document type was set as all document types, and language as all languages. The title (TI) and topic (TS) were specified as the above to focus on restoration of freshwater ecosystems, based on the experience with literature that these terms allow us to nearly pick up all the relevant papers. Since the country where a restoration project or research has 
been undertaken is almost likely consistent with the authors' country, we limited the "CU" to China to rule out the research done in other countries.

Manual screening and categorizing

The targeted publications were manually screened to identify research that presented actual full-scale restoration projects in field, and monitored and evaluated of restoration outcome. The pilot-scale studies conducted in laboratory were excluded. Furthermore, reviews and general strategic or policy discussions without specific cases studies were ruled out. Because it was indicated that a substantial proportion of the papers merely provided describing and non-quantified assessments of project outcome, these papers were also removed. Similarly, modelling analyses only focusing on model development for evaluation of restoration success without any specific projects were discarded as well.

The extracted papers were categorized with the criteria in Table 1 characterizing the publication details, background of the ecosystems, details of restoration projects, and assessments of restoration outcome. Since most of the monitoring and evaluations of project were conducted with comparisons to reference sites or controls without artificial interventions, three types of reference site were also taken into account in the paper classification: simultaneous control site without intervention, previous state before intervention, and others. The criteria used for evaluating restoration outcomes mainly included 4 sub-categories: (1) morphological or physical characteristics of ecosystem or habitat; (2) water quality; (3) biological characteristics and (4) ecological processes. The criteria of the first sub-category included hydrological parameters (i.e. flow velocity and hydraulic dynamics), sediment/soil characteristics, structural stability, and diversity and integrity of habitat. The second sub-category included COD, BOD, transparency, TSS, DO, nutrients, metals, POPs, pathogens and other chemical variables. The third sub-category included biodiversity, species richness, population and biomass of organisms. The fourth sub-category included primary and secondary production, nutrient dynamics, organic matter cycling, food web diversity, et al. The fifth sub-category included aquatic production, navigation, aesthetic and educational value, etc. Depending on whether changes in the 
monitored criteria after a project indicated progress towards the restoration goal, the outcome was classified into "improved (Yes)", "not improved (No)", and "not decided due to the inconsistent changing pattern of monitored indicators (Hard to decide)". Number and ratio of papers classified into the criteria under each category were recorded.

Table 1 Categories and criteria of literature classification

\begin{tabular}{|c|c|c|}
\hline $\begin{array}{l}\text { Categories } \\
\text { Publication details }\end{array}$ & Sub-categories & $\begin{array}{l}\text { Criteria } \\
\text { Publishing year } \\
\text { Journal } \\
\text { Language }\end{array}$ \\
\hline $\begin{array}{l}\text { Background } \\
\text { information of } \\
\text { ecosystem }\end{array}$ & & $\begin{array}{l}\text { Ecosystem type } \\
\text { Project location (province or city) } \\
\text { Type of ecosystem } \\
\text { Degradation cause }\end{array}$ \\
\hline \multirow[t]{3}{*}{$\begin{array}{l}\text { Details of } \\
\text { restoration } \\
\text { project }\end{array}$} & & $\begin{array}{l}\text { Spacial scale of project or } \\
\text { research } \\
\text { Duration of artificial intervention }\end{array}$ \\
\hline & & $\begin{array}{l}\text { Duration of monitoring } \\
\text { Restoration goal }\end{array}$ \\
\hline & & Restoration measures \\
\hline \multirow[t]{5}{*}{$\begin{array}{l}\text { Evaluation of } \\
\text { restoration } \\
\text { outcome }\end{array}$} & $\begin{array}{l}\text { Morphological or physical } \\
\text { characteristics of ecosystem or } \\
\text { habitat }\end{array}$ & $\begin{array}{l}\text { Hydrological parameters (i.e. flow } \\
\text { velocity and hydraulic dynamics) } \\
\text { Sediment/soil characteristics } \\
\text { Structural stability } \\
\text { Diversity and integrity of habitat }\end{array}$ \\
\hline & Water quality & $\begin{array}{l}\text { Physicochemical parameters } \\
\text { (transparency, TSS, DO, pH, etc.) } \\
\text { COD and BOD } \\
\text { Nutrients } \\
\text { Metals } \\
\text { Organic pollutants } \\
\text { Pathogens }\end{array}$ \\
\hline & Biological characteristics & $\begin{array}{l}\text { Biodiversity and species richness } \\
\text { Abundance } \\
\text { Community structure } \\
\text { Presence of endangered species }\end{array}$ \\
\hline & Ecological processes & $\begin{array}{l}\text { Primary and secondary } \\
\text { production } \\
\text { Cycling of nutrient and organic } \\
\text { matter } \\
\text { Food web diversity }\end{array}$ \\
\hline & Socioeconomic benefits & $\begin{array}{l}\text { Aquatic production, navigation, } \\
\text { aesthetic and educational value, } \\
\text { etc. }\end{array}$ \\
\hline
\end{tabular}


Data analyses

In order to explore the impact of socioeconomic development on FER practice in China, statistical data of population, GDP growth, water resource, amount of wastewater discharge, and investment into water pollution control of each province were obtained from the website of National Bureau of Statistics of China (NBSC). The selection of these socioeconomic indices is supported by the following assumptions: (1) with an increasing population and wastewater discharge, ecological issues will be increasingly more severer, consequently provoking more investment into environmental pollution control; (2) economic growth relates positively to the production of applied ecological research and practice. The correlations between number of filter papers and the socioeconomic variables were respectively analyzed as a function of year.

Since the preliminary result of the analysis indicated that the distribution of projects in province was extremely uneven, we classified all provinces or cities of China into 6 regions as shown on the website of NBSC: Northeast, North, East, Northwest, Southwest and Central south. The correlations between the number of published papers and the socioeconomic indices in the level of region were analyzed.

\section{Results}

Temporal and regional distribution of FER studies

A total of 2047 publications have been targeted in the literature searching, most of which were published after 2002. After the manual screening, 198 publications were remained to be categorized, and 67 of them were in English, the rest were in Chinese. Similar to the temporal distribution of the unscreened publications, the number of filtered papers showed a general growing pattern with time, increasing from 6 in 2003 to 18 in 2007, and experienced a valley point between 2009-2010 with numbers less than 10, then increased again to 22 in 2017 (Fig. 1). 
The regional distribution of the publications was highly uneven across the provinces and regions. More than half (54.0\%) of the filtered studies were performed in the eastern region, and $20.2 \%$ in the central southern area (Fig. 2). The rest areas, including North, Northeast, Northwest and Southwest, totally contribute only 1/4 (25.8\%) of the studies. The centralization of studies in the eastern region was reasonably related to the biggest population and GDP contribution in this region. Correlations among the socioeconomic indices and the numbers of filter FER publications indicated that, the publication number was significantly correlated with the regional population, GDP growth, wastewater discharge and investment into water pollution control, but had no relation with the water resources in the region (Table 2). And as expected, there were notable correlations among population, GDP, wastewater discharge and investment into water pollution control.

Table 2 Correlations among socioeconomic indices of each region in 2017 and the numbers of filter freshwater ecological restoration publications.

\begin{tabular}{llllll}
\hline $\begin{array}{l}\text { Correlation } \\
\text { coefficient }\end{array}$ & GDP & $\begin{array}{l}\text { Water } \\
\text { resource }\end{array}$ & $\begin{array}{l}\text { Wastewater } \\
\text { discharge }\end{array}$ & $\begin{array}{l}\text { Investment into } \\
\text { water pollution } \\
\text { control }\end{array}$ & $\begin{array}{l}\text { FER } \\
\text { publication } \\
\text { number }\end{array}$ \\
\hline Population & $0.972^{* * *}$ & 0.405 & $0.996^{* * *}$ & $0.819^{*}$ & $0.902^{*}$ \\
GDP & & 0.197 & $0.979^{* * *}$ & $0.923^{* *}$ & $0.968^{* * *}$ \\
Water resource & & & 0.360 & -0.068 & 0.098 \\
\hline $\begin{array}{l}\text { Wastewater } \\
\text { discharge }\end{array}$ & & & & $0.845^{*}$ & $0.924^{* *}$ \\
\hline $\begin{array}{l}\text { Investment into } \\
\text { water pollution } \\
\text { control }\end{array}$ & & & & & $0.977^{* * *}$ \\
\hline
\end{tabular}

* Indicates $\mathrm{P}<0.05, * *$ Indicates $\mathrm{P}<0.01, * * *$ Indicates $\mathrm{P}<0.001$.

Details of the FER projects

Fig. 3 indicated that nearly half of the FER practice studies have been conducted in lakes (46.5\%), followed by estuaries (15.2\%) and channels (13.6\%). Surprisingly, the proportion of project research completed at large rivers is only $7.6 \%$, lower than that in 
marshes/swamps (9.1\%). The biggest two causes of ecological degradation were land reclamation (accounting for 35\%) and eutrophication (33\%), water pollution alone was merely the third cause (12\%). Moreover, water shortage was not one of the major reasons leading to the degradation of freshwater ecosystems, not consistent with some previous reviewing literatures. The scale of FER projects were mainly river reaches or lake regions, accounting for $75 \%$ of the total number of the studies, only a small part of the studies were conducted in whole ecosystems (12\%) or watersheds (2\%). More than $60 \%$ of the studies simultaneously monitored the sites or points without intervention as the references to evaluate the restoration outcome, and $28.8 \%$ compared the status before and after the projects to decide whether there were progresses made with the restorations.

The goals of the restoration projects predominantly focused on improving biodiversity (31.4\%), water quality (24.7\%) and ecosystem services (23.9\%). Other goals include protecting endangered species, stabilizing physical structure of ecosystems, improving nutrient cycling, invasive species control, etc., only accounting for $20 \%$ (Fig. 4). About $40 \%$ of the filter studies applied revegetation as the main approach to restore the freshwater ecosystems, while much less proportions of studies employed physical or chemical measures (17.2\%) and biomanipulation (11.4\%).

The restoration intervention and monitoring period have also been recorded in the publication classification. The artificial intervention put into the restoration did not have long period. Nearly half of the studies indicated a period of continuous restoration intervention shorter than one year and about 1/3 had 1-5 year intervention (Fig. 5A). Only $12 \%$ and $10 \%$ of the studies showed $6-10$ and $>10$ years of intervention duration. Similar to the intervention period, the monitoring period was also short, with $55 \%$ of studies having $<1$ year monitoring duration, and only approximately $1 / 3$ having $1-5$ years of monitoring (Fig. 5B).

Outcome evaluation of FER projects

Given the multiple restoration goals, the indices considered in the assessments of project outcome were accordingly diverse, which were categorized to 4 major dimensions as 
described above. The most predominant aspect considered in evaluating improvements achieved on the physical or morphological dimension was the characteristics of sediment or soil, followed by hydrological dynamics (Fig. 6A). Habitat diversity was also an important factor, generally specified with diversity of environmental conditions of the ecosystems. For the studies aiming at antierosion of bank, or landscape effect, the slope stability or channel form were also considered. More than half of the studies (58\%) showed positive results in terms of the these monitored indices. However, due to the incompatibility of the changes in different indices, $1 / 3$ of the studies did not indicate precise results.

For the projects addressing water quality improvement, the most frequently monitored parameters included nutrient, chemical oxygen demand (COD), transparency and dissolved oxygen (DO), among which nutrients (nitrogen and phosphorus in particular) were absolutely the dominant factor, accounting for $32 \%$ of the publication number (Fig. 6B). Most of these studies made progresses on water quality improvement (86\%), namely the concentration of nutrients, COD, BOD, TSS and so on declined, transparency and DO increased. There was still a small proportion of studies showing ambiguous feedbacks for water quality improvement.

Most of the studies monitored the traditional ecological indices including species richness, population, biomass and biodiversity (Fig. 6C). Macrophtes were one of the most frequently monitored organisms, which had a ratio of $31 \%$ in all organisms involved in evaluating the biological outcomes of FER project. Phytoplankton and benthos were also the other biological classes regularly appeared in the monitoring and evaluation work. Neary $80 \%$ of papers achieved notable improvement in biological characteristics.

Apart from the traditional biological indices, some ecological processes or function, e.g., nutrient cycling, organic dynamics, primary production, food web, and other ecosystem services were also considered in a few studies (Fig. 6D). Among them, nutrient cycling and organic dynamics were the two predominant factors evaluated in these projects. And similarly, $85 \%$ of the papers showed good performance in improving the biological processes and functions. 


\section{Discussion}

\section{Growth of FER studies with time and socioeconomic development}

The growth of FER research and practices with time is approximately consistent with the deterioration of water quality and ecological functions in freshwater ecosystems. During the first five years of 21 century, the water qualities of surface freshwater exhibited the worst status. Meanwhile, the freshwaters were also facing increasingly serious issues, such as habitat losses, species extinction, ecological invasion, ecosystem service decline, and so on $[16,30,36,44]$. That is also when a number of nation-wide FER projects have been launched to alter the situation (e.g., Major National Scientific and Technological Projects on Water Pollution Control and Treatment). The rapid increase in FER studies during the same period (Fig. 1) was mostly the outcome of these projects and efforts. The studies conducted in Suzhou River, Shanghai and Taihu Lake, Jiangsu Province contributed the majority of publications in the East China, which is inevitably ascribed to the severity of water pollution of these two waters. Additionally, the regional GDP and investment into environmental protection had significant correlations with the number of FER studies (Table 1), highlighting the importance of overall economic development and financial investment into the scientific research and environmental protection $[12,23]$.

\section{Quantitative details of the FER projects}

Almost half of the FER studies were conducted in lakes (Fig. 3A), which was likely associated with the bigger pressure from improving the deteriorated water qualities in the large lakes compared to other ecosystem types. And it in some way reflects the fact that it is more difficulty to perform small-scale projects or studies in large running waters. In most studies in which the authors mentioned about the causes of ecosystem degradation, the predominant causes are land reclamation and eutrophication (Fig. 3B), which is consistent with what we mentioned in the introduction.

Most restoration projects are completed at reach scale for rivers and area scale for lakes, the ratio of studies at watershed scale is only $2 \%$ (Fig. $3 \mathrm{C}$ ). It is associated with the fact that, in the past decade, many FER projects were implemented as demonstrations of the national wide and government-driven projects aiming to mitigate water pollution and ecological degradation. The disassembling of watershedscale planning and over-dispersed investment and management result in the relatively small scales of restoration project. However, there is no doubt that an effective restoration requires coordinated efforts at the watershed, because the sources of impacts to ecosystems are largely generated outside of the freshwaters in the watershed, thus restoration potential may be very limited when entire watersheds are impaired [26, 37]. The tangling of property ownership, expectation for socioeconomic development from the government, interest demand from the public, and the investment mechanism, usually complicates the planning, implementation and evaluation of the restoration projects at the watershed level. Thus, it requires more interactions between different interest groups, more profound pre-restoration planning, and longer-term and bigger-scale monitoring for the watershed-scale FER projects. 
Over $60 \%$ of the studies assesse the project outcome by comparing to a reference site as the simultaneous control without intervention (Fig. 3D). This is particularly the case if the pre-restoration information about the ecological status is lacking. Actually, for the studies using the status before restoration as the reference, the "status before restoration" in most cases does not necessarily refer the status before degradation, and most project outcome assessments have just suggested whether the restoration actions worked compared with the situation without them.

The most frequently mentioned goals of restoration are improvement of biodiversity and water quality, and ecosystem services (Fig. 4A). The emphasize on biodiversity and water quality is similar with what was found in the study reviewing on the status of river restoration in the United States by Palmer et al. [24], while the difference is that the goals related to stabilizing channels, improving riparian and in-stream habitat for the US projects account for considerable percentages in the overall projects. Additionally, the methods used in our FER projects are dominated by revegetation (accounting for over 40\%, Fig. 4B), which is greatly different from the focus on geomorphic measures for channels and streams in the US projects. It is partly ascribed to the popularity of the Natural Channel Design (NCD) approach for river restoration in the US in $20^{\text {th }}$ century [27]. The broad application of revegetation as an restoration measure has its practical cause. Although spontaneous colonization by plants, following habitat recovery, is normally preferred, sometimes the re-introduction of native pioneer species is necessary in case the habitats are isolated or fragmented, or the seed bank is lacking [22].

Time scale of the intervention and monitoring are typically shorter than 1 year (Fig. 5). Since most biogeochemical and ecological processes delay the responses of freshwater ecosystems to the interventions, potentially for decades [7], it is important to recognize that some restoration goals may only be achieved in a long run, which make the short-term monitoring compromising in offering substantial evidences underpinning the solid conclusions about whether the project outcomes are positive. Thus, the expanded duration, at least of post-restoration monitoring is needed to support the evaluation of FER outcomes.

\section{Outcome evaluation of the FER projects}

Defining the success of a restoration project has always been an issue for restoration ecologists [24], and the main categories and key attributes that used to evaluate the outcome of the FER projects have been kept revised and updated during the past years. Besides of morphological and physical characteristics, water quality, biological characteristics and ecological processes, the categories of metrics for evaluating the outcome of FER projects we used in this study also include socioeconomic benefits (Table 1). However, only 3 publications provided direct results concerning economic benefit from the restoration projects. Unlike the most previous studies which mainly used morphological or physical characteristics as indicators, our study shows that biological characteristics and water quality are the most commonly used categories for outcome evaluations (Fig. 6), and at least nearly $80 \%$ of the publications provided 
positive results based on the improvement of the monitored indicators, which can be considered to meet the restoration goals.

Although numerous studies of stream or river restoration indicate that the restoration of channel form and stream bank can lead to rehabilitation of physical habitat, biological recovery is not common even when the in-stream/channel structural variables are completely restored. Simply, habitat may be important ecologically, but it is not sufficient for assessing ecological outcomes, and in the vast majority of cases restoration of habitat does not certainly lead to biological restoration [9]. In fact, as one of the most frequently considered categories in evaluating the restoration effectiveness in our study, water quality usually limits the biological recovery of freshwaters, and thus ecological recovery will not occur until the source of pollutant is removed [11]. Many studies show and interpret the relationships between nutrient levels and ecological structure and function in freshwater ecosystems, and it is the classic theory of eutrophication of shallow lakes underpinning the most of FER practices in China.

In most projects aiming to improve water quality, physical/chemical measures and revegetation are employed, and in most cases, they are proved to be efficient in achieving the goal in our study. However, the pollution mitigations are typically carried out at relatively small scales (e.g., river section or lake region), and the monitoring of water quality and ecological status is almost accordingly conducted within limited spatial and temporal ranges (Fig. 5B), which makes whether the restoration effect can exists in a broader range and a longer term questionable. While, the best management practices at a watershed scale may reduce and delay pollution to the waterbodies and may improve water quality conditions and ultimately restore the ecological processes successfully [28]. But the number of projects focusing on the watershed-scale restoration is still small over the past decades (Fig. 3C), not only in China but across the global $[17,20]$. However, there is an increasing number of FER studies starting to include larger-scale and longer-term targets, which is hopeful for more thoroughly understanding restoration ecology and better FER practice.

\section{Conclusions}

The present literature research indicated that economic growth, water pollution and investment into environmental protection are the main driving factors of FER practice in China. Additionally, the effort of restoration and evaluation over the past two decades has not been limited to improving hydrological function and water quality, but also pay increasingly more attention to biological processes and ecological integrity, and further the ecosystem services in recent years. However, the lack of long-term monitoring and socioeconomic attributes considered in restoration success assessments are still particular issues needed to be addressed in the future FER researches and projects.

\section{Abbreviations}

FER: freshwater ecological restoration; CNY: China Yuan; CSCD: Chinese Science and Citation Database; NBSC: National Bureau of Statistics of China; GDP: gross domestic product; COD: chemical oxygen 
demand; BOD: biochemical oxygen demand; TSS: total solid substance; DO: dissolved oxygen; POPs: persistent organic pollutants.

\section{Declarations}

\section{Acknowledgements}

The paper is based on the projects initiated and financed by the National Natural Science Foundation of China (No. 51778455) and the National Major Program of Science and Technology (2017ZX07603-003).

\section{Authors' contributions}

All authors contributed to the conception and design of the study. The literature search, manual screening, analyses and the manuscript writing were performed by JW. All authors commented and revised on the first draft of manuscript.

\section{Funding}

This study was funded by the National Natural Science Foundation of China (No. 51778455) and the National Major Program of Science and Technology (2017ZX07603-003).

\section{Availability of data and materials}

All data generated or analysed during this study are included in this published article.

\section{Ethics approval and consent to participate}

Not applicable.

\section{Consent for publication}

Informed consent was obtained from all individual participants included in the study.

\section{Competing interests}

The authors declare that they have no competing interests.

\section{References}


1. Cao S (2010) Socioeconomic road in ecological restoration in China. Environ Sci Technol 44: 53285329 .

2. Chen K N, Bao C H, Zhou W P (2009) Ecological restoration in eutrophic Lake Wuli: a large enclosure experiment. Ecol Eng 35: 1646-1655.

3. Cheng H, Hu Y (2012) Improving China's water resources management for better adaptation to climate change. Climatic Change 112: 253-282.

4. Cui B, Yang Q, Yang Z, Zhang K (2009) Evaluating the ecological performance of wetland restoration in the Yellow River Delta, China. Ecol Eng 35: 1090-1103.

5. Gao H, Shi Q, Qian X (2017) A multi-species modelling approach to select appropriate submerged macrophyte species for ecological restoration in Gonghu Bay, Lake Taihu, China. Ecol Model 360: 179-188.

6. Gong C, Xu C, Chen L, Cao S (2012) Cost-effective compensation payments: a model based on buying green cover to sustain ecological restoration. Forest Policy Econ 14: 143-147.

7. Hamilton S K (2012) Biogeochemical time lags may delay responses of streams to ecological restroration. Freshwater Biol 57: 43-57.

8. He H, Luo X, Jin H, Gu J, Jeppesen E, Liu Z, Li K (2017) Effects of exposed artificial substrate on the competition between phytoplankton and benthic algae: Implications for shallow lake restoration. Water 9: 24-32.

9. Jähnin S C, Brabec K, Buffagni A, Erba S, Lorenz A W, et al (2010) A comparative analysis of restoration measures and their effects on hydromorphology and benthic in vertebrates in central and southern European rivers. J Appl Ecol 47: 671-

10. Ji Y X, Huang M S, Wei Z X, Lu Z L (2008) Research and application of multi-naturalness river restoration technologies in Shanghai. Res Environ in the Yangtze Basin 17(2): 264-269.

11. Kail J, Arle J, Jähnig S C (2012) Limiting factors and thresholds for macroinvertebrate assemblages in European rivers: empirical evidence from three datasets on water quality, catchment urbanization, and river restoration. Ecol Indic 18: 63-72.

12. Kline J D, Mazzotta M J, Spies T A, Harmon M E (2013) Applying the ecosystem services concept to public land management. Agr Resour Econ Rev 42(1): 139-158.

13. Kollmann J, Meyer S T, Bateman R, Conradi T, et al (2016) Integrating ecosystem functions into restoration ecology-recent advances and future directions. Restor Ecol 24(6): 722-730.

14. Li X P, Zhang L, Zhang Z (2006) Soil bioengineering and the ecological restoration of riverbanks at the Airport Town, Shanghai, China. Ecol Eng 26: 304-314.

15. Liu S, Dong Y, Cheng F, Coxixo A, Hou X (2016) Practices and opportunities of ecosystem service studies for ecological restoration in China. Sustain Sci 11: 935-944.

16. Lu X N, Deng W, Zhang S Q (2007) Flood pulse concept and its application. Chinese J Ecol 26(2): 269-277.

17. Ma H, Lv Y, Li H (2013) Complexity of ecological restoration in China. Ecol Engin 52: 75-78. 
18. Mi Y J, He C G, Bian H F, Cai Y P, Sheng L X, Ma L (2014) Ecological engineering restoration of a nonpoint source polluted river in Northern China. Ecol Eng 76: 142-150.

19. Ministry of Environmental Protection. http://www.mee.gov.cn. Accessed on 20 July 2019.

20. Montoya D, Rogers L, Memmott J (2012) Emerging perspectives in the restoration of biodiversitybased ecosystem services. Trends Ecol Evol 27(12): 666-672.

21. National Bureau of Statistics of China. http://data.stats.gov.cn/easyquery.htm?cn=C01. Accessed 21 August 2018.

22. Nienhuis P H, Bakker J P, Grootjans A P, Gulati R D, de Jonge V N (2002) The state of the art of aquatic and semi-aquatic ecological restoration projects in the Netherlands. Hydrobiol 478: 219-233.

23. Nuñez M A, Barlow H, Cadotte M, Lucas K, Newton E, Pettorelli N, Stephens P A (2019) Assessing the uneven global distribution of readership, submissions and publications in applied ecology: Obvious problems without obvious solutions. J Appl Ecol 56: 4-9.

24. Palmer M A, Hondula K L and Koch B J (2014) Ecological restoration of streams and rivers: shifting strategies and shifting goals. Annu Rev Ecol Evol Syst 45: 247-269.

25. Pan G, Yang B, Wang D, Chen H, Tian B, Zhang M, Yuan X, Chen J (2011) In-lake algal bloom removal and submerged vegetation restoration using modified local soils. Ecol Eng 37: 302-308.

26. Parkyn S M, Smith B J (2011) Dispersal constraints for stream invertebrates: setting realistic timescales for biodiversity restoration, Environ Manage 48(3): 602-614.

27. Rosgen D (1998) Applied stream geomorphology. Widland Hydrol, Pagoda Springs.

28. Selvakumar A, O'Connor T P, Struck S (2010) Role of stream restoration on improving benthic macroinvertebrates and in-stream water quality in an urban watershed: Case study. J Environ Eng 136: 127-139.

29. Song K, Wang Z, Li L, Tedesco L, Li F, Jin C, Du J (2012) Wetlands shrinkage, fragmentation and their links to agriculture in the Muleng - Xingkai Plain, China. J Environ Manage 111: 120-132.

30. Song X, Lv X (2009) A review on the ecological restoration of degraded estuaries wetlands in China. Wetl Sci 7(4): 379-384.

31. State Forestry Bureau (2014) Wetland resources of China (2009-2013). Beijing.

32. Tang W, Mao Z, Zhang H, Shan B, Zhao Y, Ding Y (2015) Water resources: the prerequisite for ecological restoration of rivers in the Hai River Basin, northern China. Environ Sci Pollut R 22: 13591365.

33. Wang G X, Zhang L M, Chua H, Li X D, Xia M F, Pu P M (2009) A mosaic community of macrophytes for the ecological remediation of eutrophic shallow lakes. Ecol Engin 35: 582-590.

34. Wang H, Ma M (2016) Impacts of climate change and anthropogenic activities on the ecological restoration of wetlands in the arid regions of China. Energies 9: 166-190.

35. Wang W, Tang X Q, Huang S L, Zhang S H, Lin C, Liu D W, Che H J, Yang Q, Scholz M (2010) Ecological restoration of polluted plain rivers within the Haihe River Basin in China. Water Air Soil Poll 211: 341-357. 
36. Wang Z, Huang N, Luo L, Li X, Ren C, Song K, Chen J M (2011) Shrinkage and fragmentation of marshes in the West Songnen Plain, China, from 1954 to 2008 and its possible causes. Int J Appl Earth Obs 13: 477-486.

37. Wortley L, Hero J-M, and Howes M (2013) Evaluating ecological restoration success: A review of the literature. Restor Ecol 21(5): 537-543.

38. Wu J, Cheng S, Li Z, Guo W, Zhong F, Yin D (2013) Case study on rehabilitation of a polluted urban water body in Yangtze River Basin. Environ Sci Pollut 20: 7038-7045.

39. Xie D, Zhou H, Ji H, An S (2013) Ecological restoration of degraded wetlands in China. J Res Ecol $4(1): 63-69$.

40. Yu G, Huang H Q, Wang Z, Brierley G, Zhang K (2012) Rehabilitation of a debris-flow prone mountain stream in southwestern China- strategies, effects and implications. J Hydrol 414: 231-243.

41. Yu G, Wang Z Y, Zhagn K, Duan X, Chang T C (2010) Restoration of an incised mountain stream using artificial step-pool system. J Hydraul Res 48(2): 178-187.

42. Yu J, Liu Z, Li K, Chen F, Guan B, Hu Y, et al (2016) Restoration of shallow lakes in subtropical and tropical China: response of nutrients and water clarity to biomanipulation by fish removal and submerged plant transplantation. Water 8: 438-450.

43. Zhang X, Liu X, Wang H (2014) Developing water level regulation strategies for macrophytes restoration of a large river-disconnected lake, China. Ecol Eng 68: 25-31.

44. Zhao D H, Lv M T, Jiang H, Cai Y, Xu D L, An S Q (2013) Spatio-temporal variability of aquatic vegetation in Taihu Lake over the past 30 years. PLOS One 8(6):1-7.

\section{Figures}




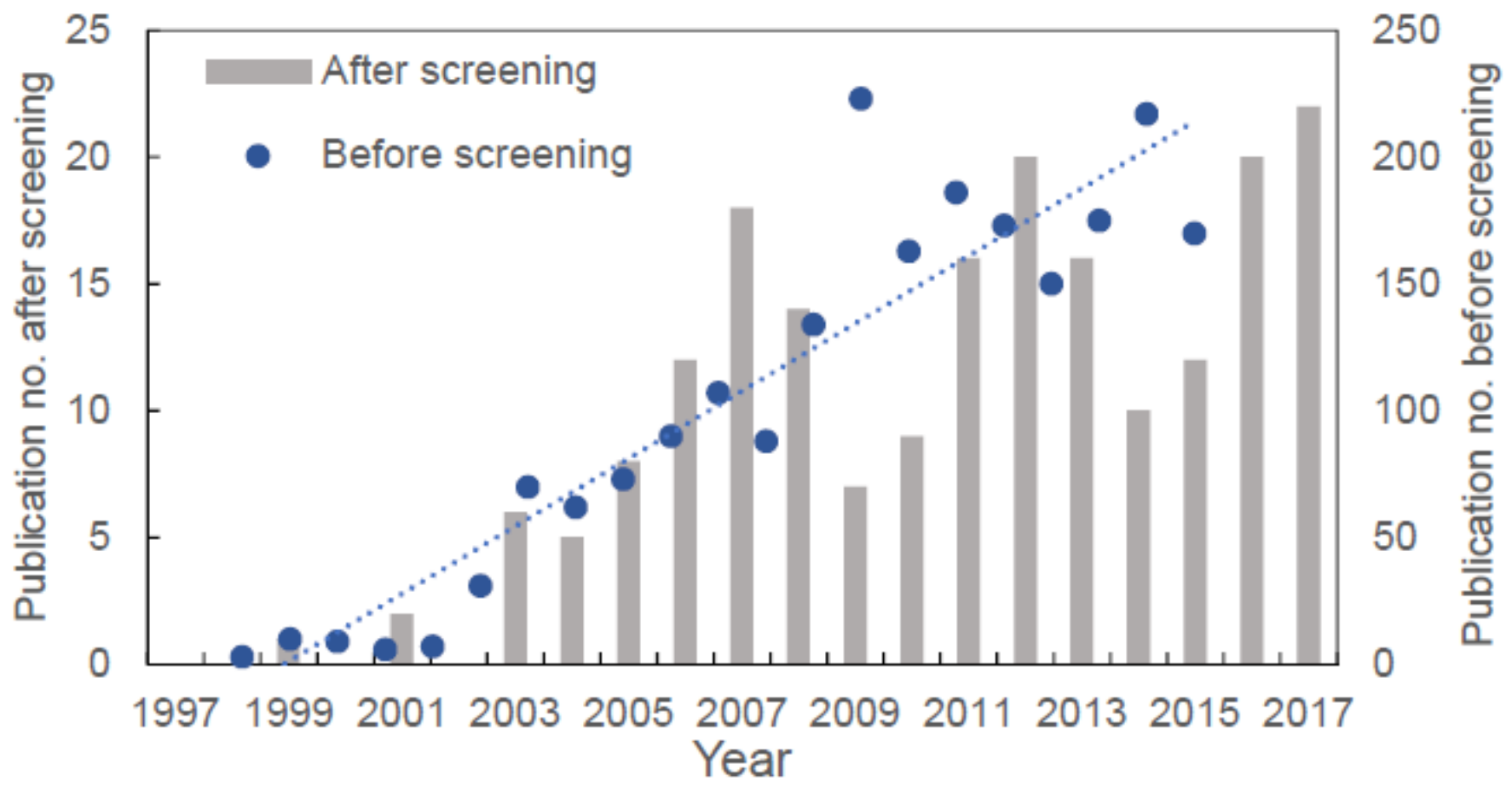

Figure 1

Changes in the number of publications of freshwater ecological restoration in China before and after manual screening

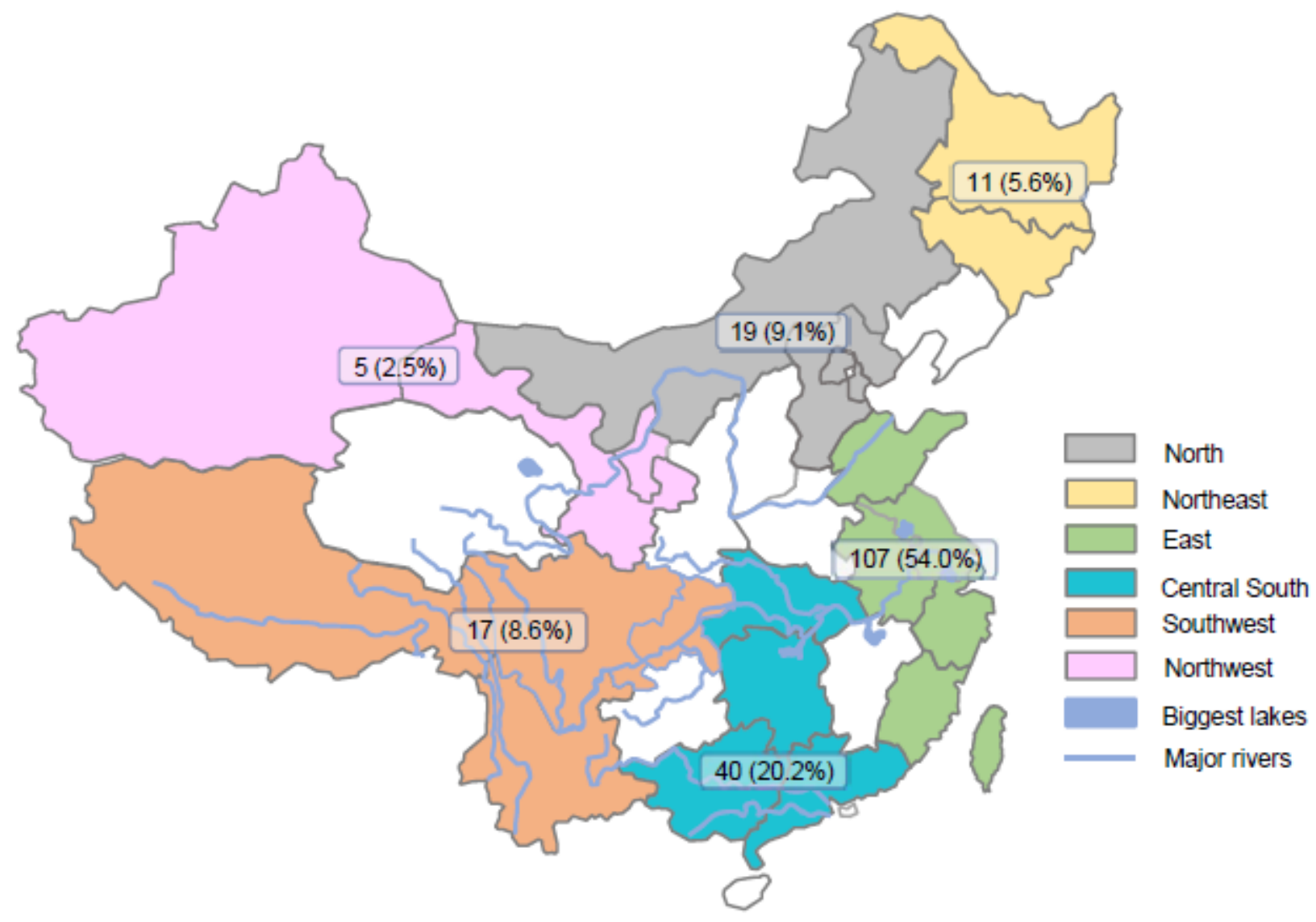




\section{Figure 2}

Regional distribution of filtered publications of freshwater ecological restoration across China. The number and percentage in each bracket on the map represent the publication number of each region and its ratio of the total publications. Note: The designations employed and the presentation of the material on this map do not imply the expression of any opinion whatsoever on the part of Research Square concerning the legal status of any country, territory, city or area or of its authorities, or concerning the delimitation of its frontiers or boundaries. This map has been provided by the authors.

A

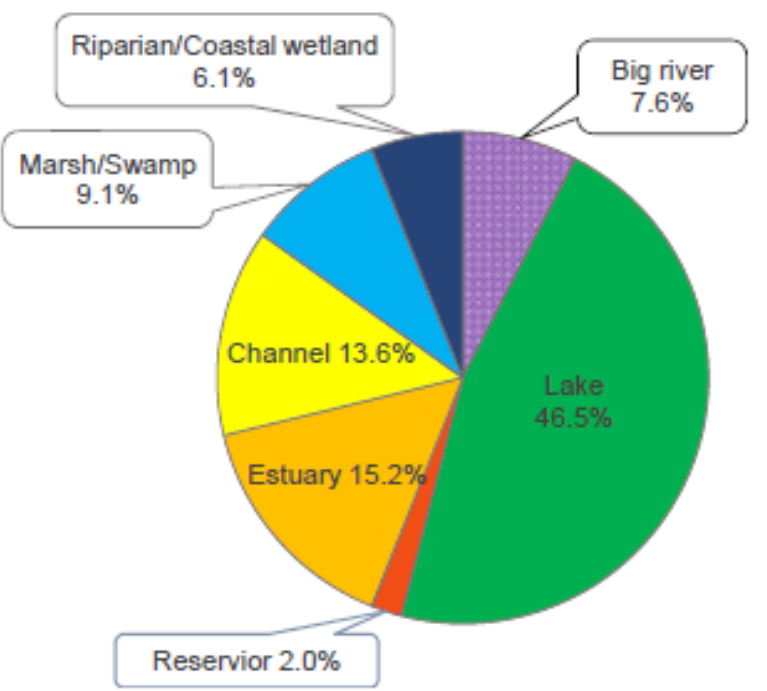

C

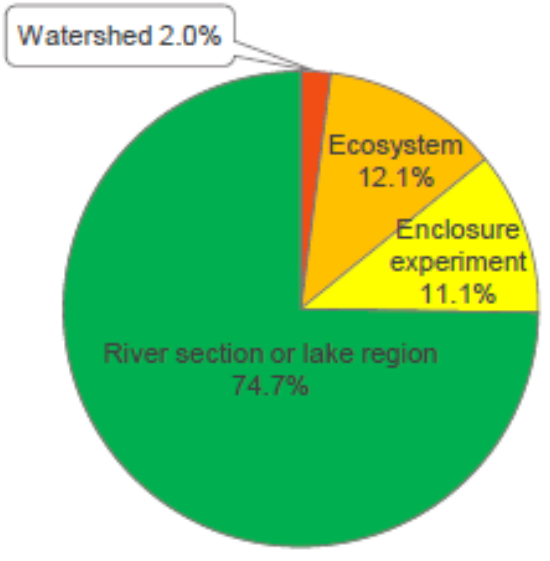

B

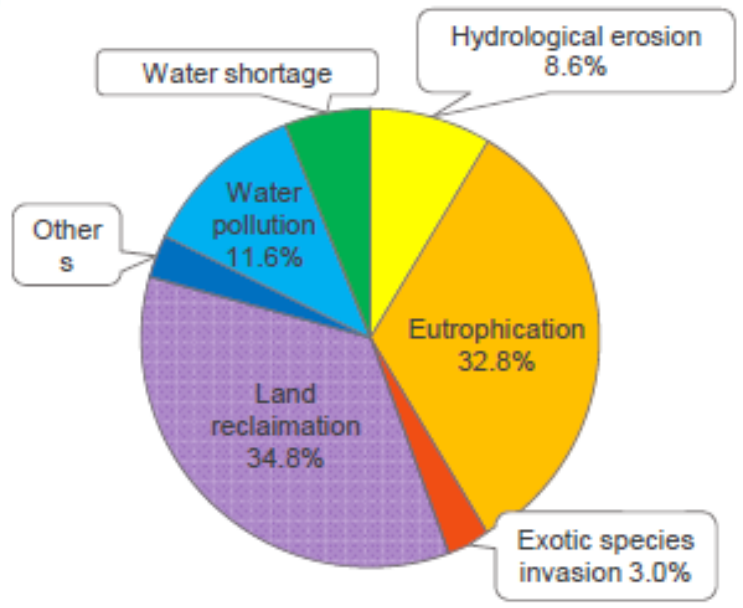

$\mathrm{D}$

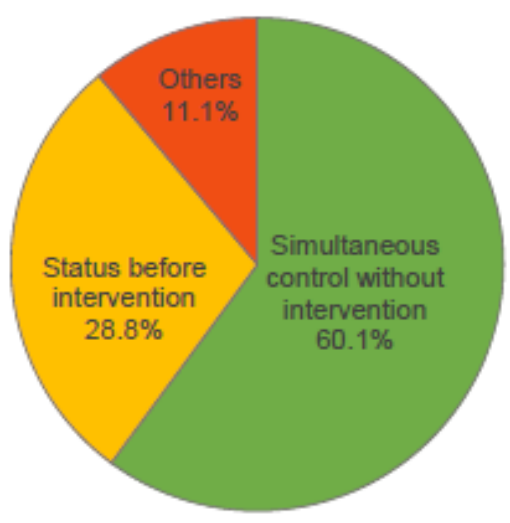

\section{Figure 3}

The ratios of publications addressing details of the FER projects including the type of targeted ecosystem $(A)$, degradation cause (B), scale of the restoration project $(C)$ and reference site for outcome evaluation (D). 
A

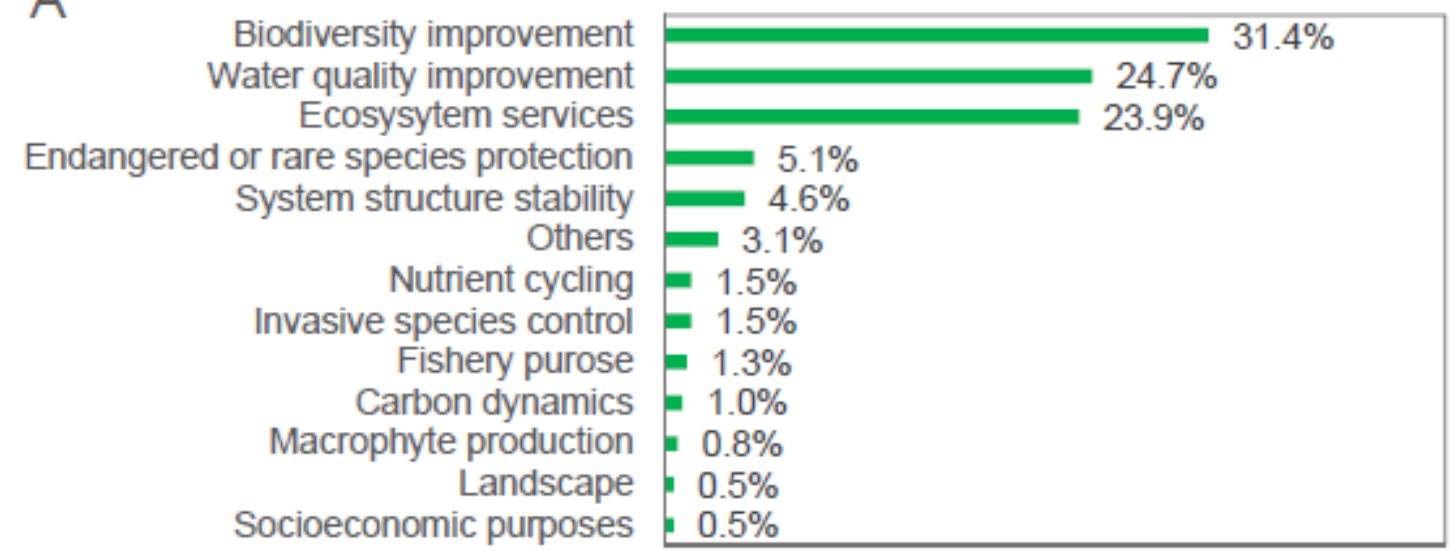

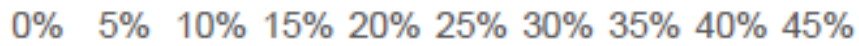

B

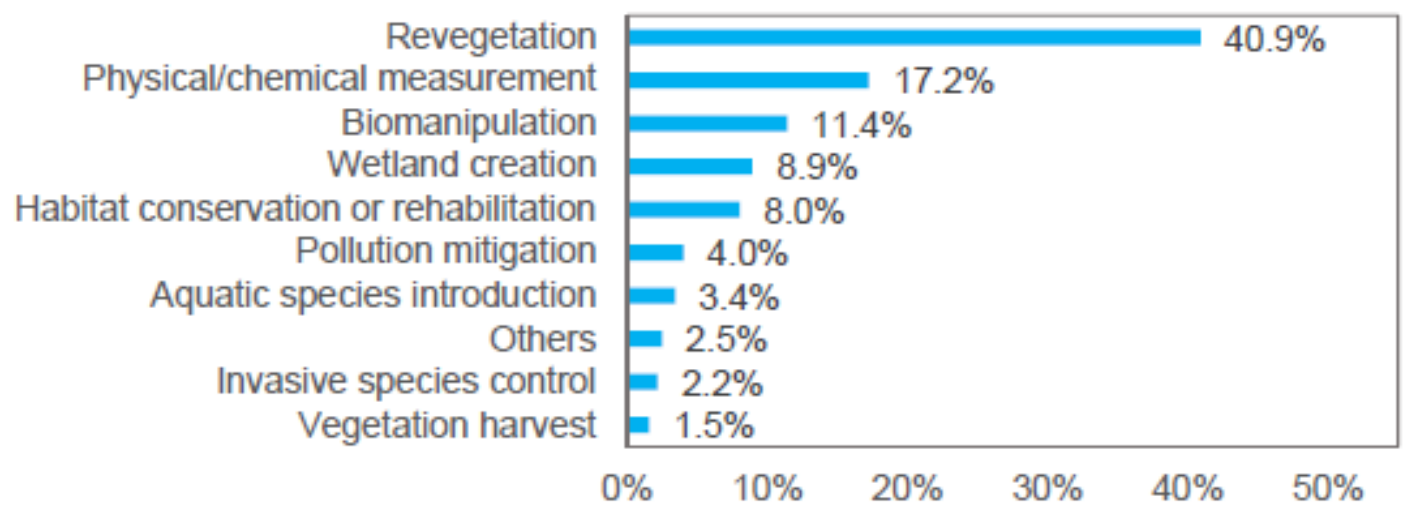

Figure 4

The ratios of publications presenting different restoration goals $(A)$ and applying different restoration measures (B). 

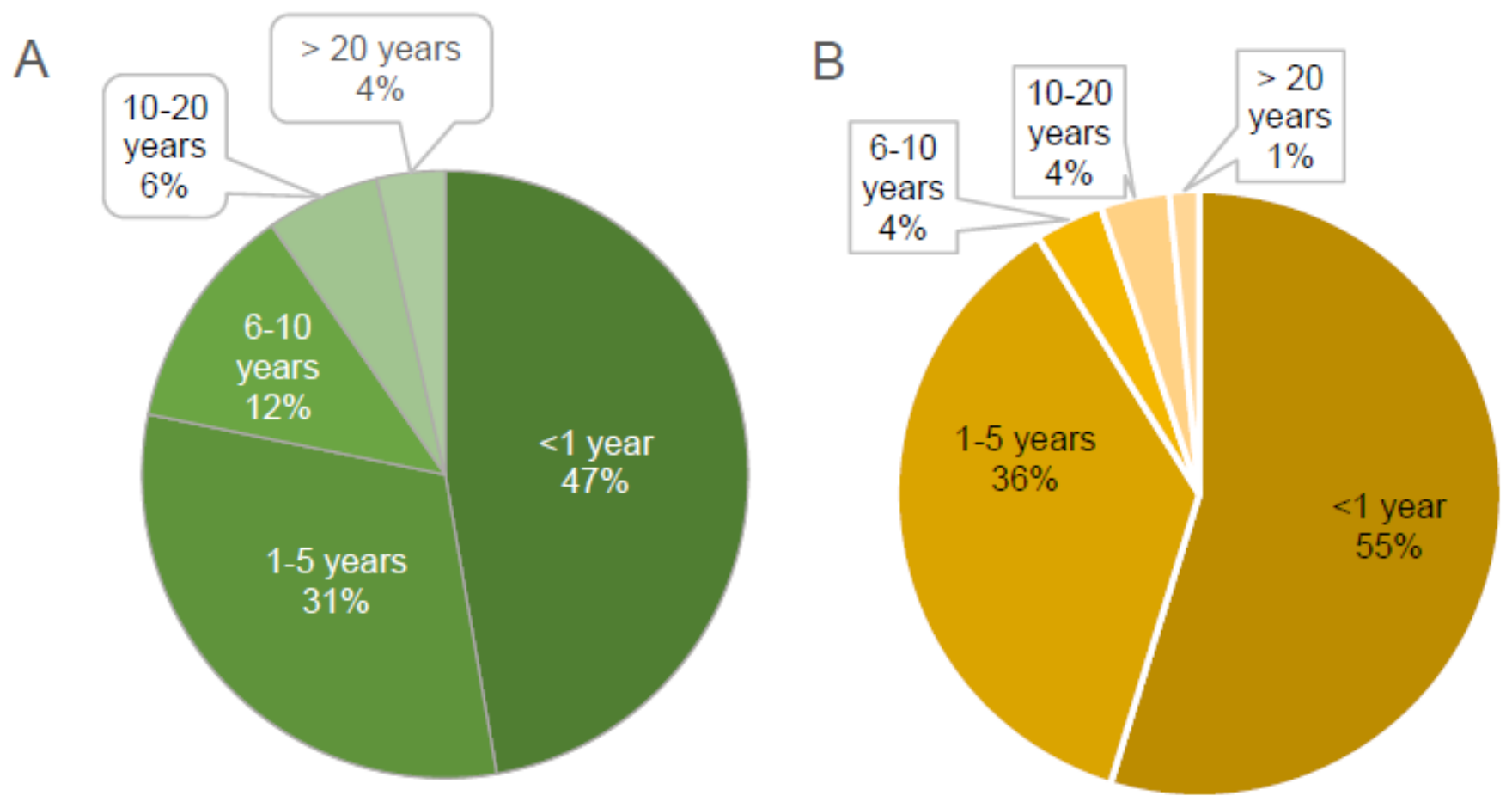

Figure 5

The ratios of publications indicating different ranges of restoration intervention $(A)$ and monitoring period (B). 

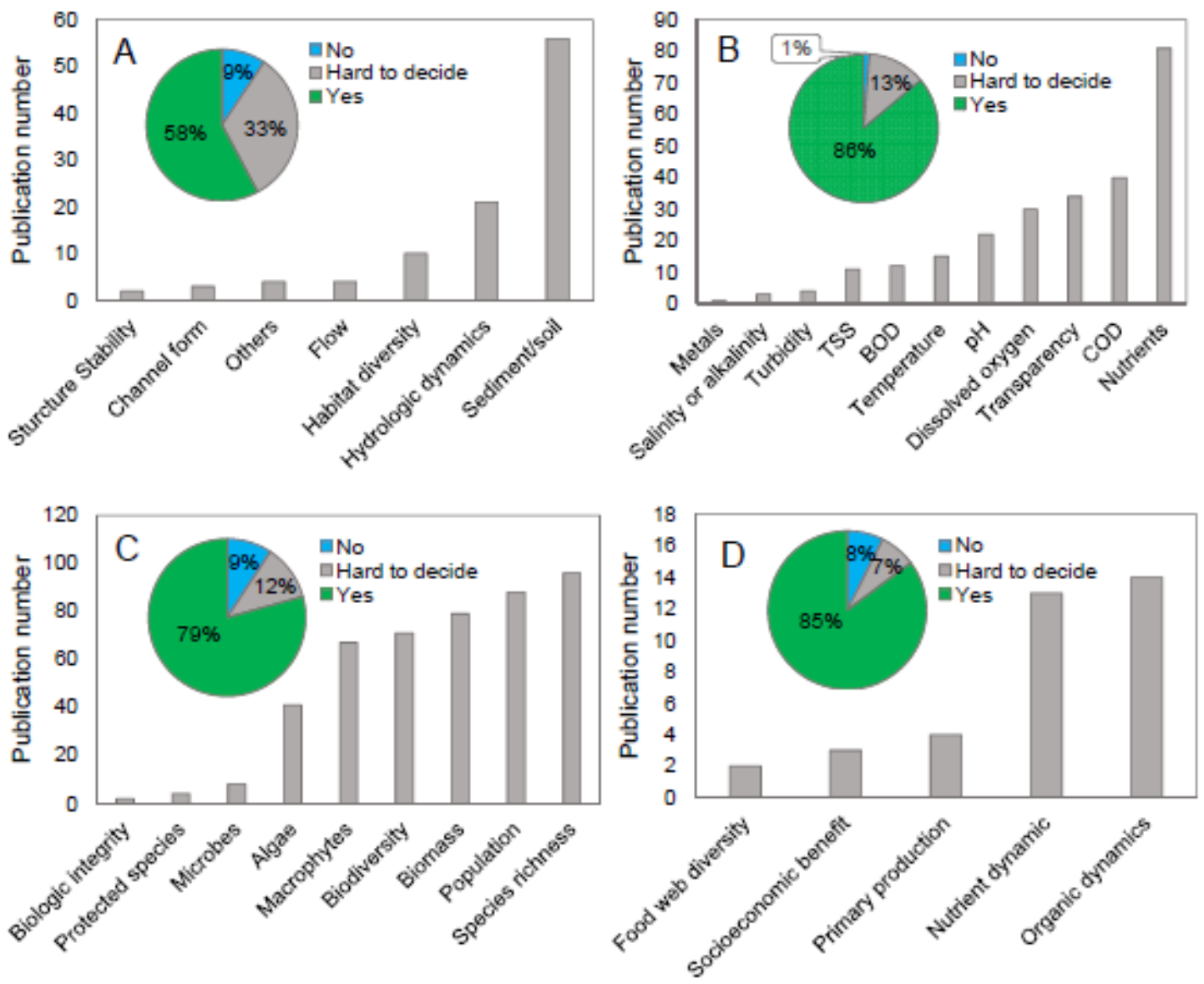

\section{Figure 6}

Number of publications presenting the outcomes of freshwater ecological restoration projects and ratios of them indicating improvement or not (A for morphological or physical characteristics, B for water quality parameters, $\mathrm{C}$ for biological metrics, and $\mathrm{D}$ for biological/ecological processes. 